\title{
A dimensão educativa da mediação artística e cultural: a construção do conhecimento através da apreciação na presença da obra ${ }^{1}$
}

\author{
Maria Regina Johann ${ }^{2}$ \\ Luciara Judite Bernardi Roratto ${ }^{3}$
}

\section{Resumo}

A dimensão educativa da mediação artística e cultural é o foco principal deste artigo, elaborado a partir da pesquisa "Mediação estética: a construção do conhecimento através da apreciação na presença da obra", que tem como espaço de realização teórico-prática a Sala de Exposição Java Bonamigo do curso de Artes Visuais da Unijuí. Questões como a educação do ver/olhar, do conhecimento sensível e cognoscível da arte, assim como, a dimensão propositiva da tarefa de mediação são abordadas no texto. Apresentamos conceitos sobre Mediação e destacamos que ela pode ser entendida como uma ação intencional criada com o objetivo de inter-relacionar, aproximar, viabilizar, esclarecer, desvelar e informar acerca da arte e da cultura, ampliando a significação sobre a obra.

Palavras-chave: arte, cultura visual, mediação, educação do ver/olhar, apreciação artística, experiência estética, conhecimento.

\begin{abstract}
The educative dimension of the cultural and artistic mediation is the main focus of this article, built from the research "Aesthetic Mediation: the building of knowledge through the appreciation in the presence of the work", which happens in a practice-theoretical way in the Java Bonamigo exhibition Room of the Visual Arts course of Unijuí University. Questions as the see/look education, the art's sensitive and cognizant knowledge, such as the proponent dimension of the mediation task are approached by this text. We present concepts on Mediation and also highlight that it can be understood as an intentional action created to inter-relate, approach, make possible, clarify, conduct and inform about arts and culture, amplifying the meaning about the work.
\end{abstract}

Key-words: art, visual culture, mediation, see/look education, artistic appreciation, aesthetic experience, knowledge.

\footnotetext{
${ }^{1}$ Projeto de Pesquisa - Mediação estética: a construção do conhecimento através da apreciação na presença da obra, financiada pelo Programa de Pós Graduação, Pesquisa e Extensão da Unijuí - Universidade Regional do Noroeste do Estado do Rio Grande do Sul. iniciou em março de 2010 sob a coordenação da professora do curso de artes visuais, Maria Regina Johann e conta com a colaboração da acadêmica do curso, Luciara Judite B. Roratto, bolsista PIBIC. Um dos objetivos desta pesquisa é ampliar a compreensão sobre a dimensão educativa da Sala de Exposição Java Bonamigo, espaço que pertence ao curso de Artes Visuais da Unijuí e que promove exposições de arte contemporânea.

${ }^{2}$ Professora do curso de Artes Visuais Licenciatura \& Bacharelado da Unijuí. Graduada em Educação Artística, Pós-graduada em Metodologia do Ensino de Arte e Mestre em Educação das Ciências. Coordenadora da pesquisa da "Mediação estética: a construção do conhecimento através da apreciação na presença da obra". Integra o grupo de artistas "Arteseis" de Ijuí.

${ }^{3}$ Acadêmica do curso de licenciatura em Artes Visuais da Unijuí e pesquisadora bolsista PIBIC da Unijuí.
} 


\section{Contextualizando a pesquisa}

O projeto de pesquisa "Mediação estética: a construção do conhecimento através da apreciação na presença da obra" consiste em realizar atividades de mediação junto à Sala de Exposição Java Bonamigo ${ }^{4}$ do Curso de Artes Visuais da Unijuí. Nela, acontecem exposições sobre arte contemporânea e cultura visual organizadas através de editais públicos e atividades curriculares do Curso de Bacharelado em Artes Visuais. Um dos princípios da Sala é o entendimento de que, para formar bons profissionais de Artes Visuais, não é necessário somente o conhecimento dos procedimentos metodológicos e didáticos. Os profissionais bacharéis e licenciados em artes visuais devem, igualmente, ser alfabetizados esteticamente, vivenciar, compreender e desenvolver uma linguagem artística e conceitual própria. Inspirada nessa ideia, a Sala Java Bonamigo surge como um espaço privilegiado para as ações educativas voltadas ao debate, apreciação, visitas e exposição dos objetos poéticos das artes visuais.

A Sala Java Bonamigo recebe anualmente um público muito expressivo de visitantes, compostos pela comunidade interna e externa, local e regional. Destaca-se, porém, a participação do público escolar, através de visitas proporcionadas pelos professores que atuam nos componentes curriculares de artes visuais, dança, teatro e música, assim como, por aqueles que atuam nos anos iniciais do ensino fundamental. Podemos afirmar que a Sala Java Bonamigo assume um lugar singular na região de Ijuí, por se constituir em um dos poucos espaços oficiais de exposições artísticas contemporâneas. Isso possibilita uma vivência com a arte que complementa os saberes construídos no âmbito da educação escolar, pois permite que o sujeito esteja na presença da obra, o que faz com que sua visualidade se amplie e a percepção artística se intensifique.

A dimensão educativa da mediação artística e cultural foi o foco principal dessa pesquisa e tivemos como propósito central apresentar as obras aos educandos e educadores ampliando o conhecimento sobre artes visuais e a cultura visual, possibilitando, assim, o entendimento da proposta artística de cada exposição.

Compreender e analisar quais os conhecimentos construídos pelos estudantes da Educação Básica a respeito das exposições foi um dos objetivos que almejamos com tal pesquisa. Igualmente, intencionamos conhecer os objetivos do(a)s professore(a)s ao trazerem seus alunos a uma exposição, observar quais os motivos para a visitação, quais os conteúdos que estão estudando e como irão contemplar, em sala de aula, as questões

\footnotetext{
${ }^{4}$ Sala de Exposição Java Bonamigo foi criada pelo Curso de Bacharelado em Artes Visuais no ano de 2004. A Sala busca atender determinação do MEC para implantação do Curso de Artes Visuais - Bacharelado -, oferecendo aos acadêmicos um espaço para exposição, pesquisa e extensão das criações visuais geradas no interior de suas atividades acadêmicas. Em pouco tempo, se torna referência na região e no interior do Estado por se tratar de um ambiente adequado, com monitoria e condições para o sucesso das exposições que abriga.
} 
apresentadas e/ou vivenciadas na exposição. Ainda, queremos pensar como podemos agregar conhecimento sobre artes visuais através das exposições (que talvez o professor não tenha planejado ou desejado abordar), interagindo com os professores na busca de uma experiência mais intensa com a arte e a cultura.

Por fim, nos interessou observar a relação do estudante com a exposição, com a proposta do artista, com os conceitos e/ou ideias apresentados no momento. A partir disso tudo, pretendemos confirmar a hipótese de que uma sala de exposição é também um lugar de aprendizagem sobre arte e cultura visual. Temos observado que, na medida em que possibilitarmos tarefas de mediação que estabeleçam relações entre artes visuais, cultura e cultura visual, cumpre-se um papel relevante na formação do gosto e na aprendizagem artística e estética, agregando conhecimento e experiência estética à vivência escolar.

\section{Mediação artística e cultural: quando os horizontes da obra e do público se aproximam}

Neste texto iremos apresentar ideias, conceitos e concepções de mediação artística e cultural a partir da revisão de algumas das bibliografias que embasaram essa pesquisa. Primeiramente, traremos o conceito de mediação apresentado por Teixeira Coelho no Dicionário Crítico de Política Cultural. Posteriormente, as referências teóricas de Miriam Celeste Martins, Ana Lisboa, Hans-Georg Gadamer, Ana Mae Barbosa, Marcia Tiburi e Fernando Hernández.

Conforme o Dicionário Crítico de Política Cultural ${ }^{5}$ (1999, p. 249), "O Mediador Cultural é um profissional com formação especializada, [...] que atua em centros de cultura, bibliotecas públicas e museus". Teixeira Coelho aponta que pode ser chamado de mediador cultural "Todo aquele que exerce atividades de aproximação entre indivíduos ou grupos de indivíduos e as obras de cultura". Porém, não encontramos o mediador somente em exposições de arte, para Coelho (1999, p. 248), podemos conhecer as áreas de atuação do mediador cultural, sendo elas "[...] orientador de oficinas culturais, monitores de exposição de arte, animadores culturais, museólogos, curadores, profissionais de diversas áreas que constituem um centro cultural, bibliotecários, arquivistas e guias turísticos". Observamos que as funções do mediador se adaptam também conforme as propostas educativas oferecidads pelos museus, galerias ou salas de exposição. Quanto mais diversificadas são as propostas pedagógicas ou expositivas, mais se ampliam as atuações dos sujeitos que atuam nesses espaços.

Caracteriza-se por promover na abertura de cada exposição debate entre artista, acadêmicos, professores e comunidade.

${ }^{5}$ Cultura e Imaginário Dicionário Crítico de Política Cultural, Teixeira Coelho, 1999. 
A relação de proximidade que se dá entre mediador e o público é essencial, pois nela acontece uma troca de experiências entre os espectadores e o profissional da área, este último levando toda sua bagagem cultural e expondo ao observador, para facilitar seu entendimento sobre as obras de arte. Essa relação possui "[...] o objetivo de facilitar a compreensão da obra, seu conhecimento sensível e intelectual - com que se desenvolvem apreciadores ou espectadores, na busca da formação de públicos para a cultura - ou de iniciar esses indivíduos e coletividades na prática efetiva de uma determinada atividade cultural" (COELHO, 1999, p. 248).

O mediador cultural é aquele que recebe o público nas instituições de arte, a fim de tornar a visitação mais significativa possível, fazendo proposições que contribuem para a interação do público com a obra. A artista e arte/educadora Ana Lisboa ${ }^{6}$ (2005) argumenta que o mediador interfere e direciona a forma como a obra de arte chega ao conhecimento do público. Lisboa (2005, p. 309) destaca que "a mediação cultural funciona como uma ponte, um elo entre o artista, sua obra e o público a que se dirige". Dessa forma, é possível afirmar que o papel do mediador é iniciar a interlocução, de provocar o observador fazendo a mediação, pois, conforme Lisboa, ele "cria uma ponte" entre o sujeito e a obra de arte. Por isso, é possível afirmar que mediação é uma prática encharcada de intencionalidade, pois ela necessita ser planejada e organizada. Não se faz mediação de forma improvisada, não basta lançar algumas questões para o público pensar, mediação é justamente o "algo a mais" que podemos fazer para que o encontro com a obra aconteça de forma mais intensa possível.

Para tanto é preciso criar um elo entre mediador e público para que se abra para a mediação. O mediador capacita a compreensão, talvez porque o que ele fala encontra ressonância no apreciador, sua memória pode encontrar "arquivos"", relacionando e inter-relacionando questões da obra com suas histórias, e assim, instigado pelo mediador, podem se formar conexões pertinentes às experiências pessoais de cada um.

Para a professora Miriam Celeste Martins ${ }^{8}$ (2005, p. 17), "[...] o papel do mediador é importante para a criação de situações onde o encontro com a arte, como objeto de conhecimento, possa ampliar a leitura e a compreensão do mundo e da cultura". Martins (2005, p. 87) faz uma criativa analogia para explicar que "[...] a mediação é como um fermento, deixando crescer algo que está dentro da própria arte". O Mediador instiga o fruidor e gera uma "coceira em suas ideias", levando-o a desejar compreender esse universo da arte que o cerca. Mesmo sem entender logo no início o

\footnotetext{
${ }^{6}$ Ana Lisboa, Construção de uma metodologia para mediação: uma experiência no Instituto de Arte Contemporânea da UFPE.

${ }^{7}$ A professora Miriam Celeste Martins (2005) usa metáforas como "arquivos", "gavetas", "expedições", "viagens" e "malas" para pensarmos sobre as "bagagens" que dispomos/convocamos quando estamos diante da obra, abertos a fruição e significação.

${ }^{8}$ Arte-educadora com formação em Artes Plásticas. Cursos de Especialização em História da Arte. O livro "Mediação: provocações estéticas" de Miriam Celeste Martins. SP, 2005, sistematiza o trabalho desenvolvido em uma disciplina sobre Mediação no Curso de Pós Graduação no Instituto de Artes/UNESP.
} 
que tal exposição oferece, o sujeito, orientado pelo mediador, abrirá seus olhos e poderá ver na arte um mundo de possibilidades.

Inspirada em Martins (2005), podemos dizer que o mediador não formula uma resposta e entrega aos espectadores, ele provoca aquele que está contemplando a obra a refletir acerca do sentido que aquela obra de arte tem em sua vida. Ele amplia e desperta o pensar do sujeito de forma que o mesmo, vai "revirando sua gaveta de guardados" e encontrando as respostas para suas dúvidas, seus questionamentos em relação à arte e à cultura visual.

Acreditamos que a ação do mediador é a de "abrir" os olhos do fruidor e fazê-lo ver coisas que sozinho não havia visto. Ele estimula o público a pensar, imaginar e criar uma leitura da obra que está em sua frente. O mediador pode ser comparado a um "óculos de grau" que, ao ser colocado, nos permitirá enxergar muito além do que antes víamos, mesmo que no início seja difícil nos acostumarmos com sua presença. $\mathrm{Na}$ mediação é assim, quando entramos em contato com o mediador, ele nos ajuda a ver elementos na obra que passaram despercebidos, possibilitando uma fantástica viagem na qual podemos relacionar o que estamos vendo com nossas vivências.

Outro elemento importante a ser considerado na tarefa de mediação, diz respeito ao argumento da professora Ana Mae $\operatorname{Barbosa}^{9}$ (2002, p. 18-19) ao afirmar que "não se trata mais de perguntar o que o artista quis dizer em sua obra, mas o que a obra nos diz, aqui e agora, em nosso contexto, e o que disse em outros contextos históricos, a outros leitores". Preocupada com estas questões, Martins nos faz refletir sobre o sentido das imagens que mostramos aos alunos e as razões que movem as escolhas do professor.

[...] o objetivo maior, então, não é simplesmente propiciar que os aprendizes conheçam apenas artistas como Monet, Picasso ou Volpi, mas que os alunos possam perceber como o homem e a mulher, em tempos e lugares diferentes puderam falar de seus sonhos e de seus desejos, de sua cultura, de sua realidade e de suas esperanças e desesperanças, de seu modo singular de pesquisar a materialidade por intermédio da linguagem da Arte. (MARTINS, 2003, p. 57)

Assim como nas aulas, devemos nos pautar por escolhas que tenham sentido para o conteúdo que estamos desenvolvendo, também na mediação isso deve ocorrer, pois as perguntas, imagens, palavras, entre outros recursos usados, devem se mover em direção à proposta da exposição e também dos assuntos por ela sugeridos. Mais do que saber o porquê do artista, devemos instigar para que o indivíduo perceba o que significa tal obra para ele, isto é, ir além de somente estudar/conhecer sobre quem a produziu e o porquê a fez.

$\mathrm{Na}$ medida em que investigamos o tema e experimentamos contextos de mediação, pode-se entender que Medição é estar entre; entre a obra e o sujeito. Mas, é um entre influenciado e influenciante. É a linha que costura o espaço que existe entre a

\footnotetext{
${ }^{9}$ BARBOSA, Ana Mae. Atualmente é professora titular aposentada da Universidade de São Paulo e professora da Universidade Anhembi Morumbi. Tem experiência na área de Artes, com ênfase em Arte/Educação, atuando
} 
obra e o público. É uma palavra, uma ideia, uma atitude que aproxima ou instiga a proximidade: proximidade do que fica velado (ou do que a obra vela), do que oculta, camufla, talvez até esconda. Mediação é ação que pretende desvelar, descortinar horizontes da obra, sem a pretensão de esgotá-la ou dizer a "sua verdade". É pretensão que nem sempre se alcança. Mediação é ação que media, é proposição que cria conexões. Mediação é busca, desconstrução e construção de significados.

Também se faz referência à mediação como algo que une dois lados, dois territórios, expressados pela metáfora da "ponte". Nesse caso, é entendida como aquilo que possibilita o deslocamento de um lugar ao outro, ou a ligação de um lado ao outro, para viabilizar o percurso e/ou passagem para chegar a um determinado lugar.

Pode ser entendida como uma ação intencional criada com o objetivo de aproximar, viabilizar, esclarecer, desvelar e informar "coisas" entre a arte e o público.

Já para Barbosa (2009, p. 13), além da arte/educação ser a mediação entre a obra e o público, a própria arte é mediação! O que a arte faz senão expressar e comunicar aquilo que as demais linguagens não possibilitam? Seria a arte uma maneira de estar no mundo habitando territórios desconhecidos, manifestando paixões materializadas em som, formas, gestos, espaços? Para Ana Mae, a importância da arte está justamente "[...] na mediação entre os seres humanos e o mundo, apontando um papel de destaque para a arte/educação: ser a mediação entre a arte e o público".

Estar na presença da obra significa olhar, ver e perceber a plasticidade da materialidade da mesma sem a padronização ou interferência dos procedimentos de reprodução, como a fotográfica, por exemplo. A experiência de estar na presença da obra proporciona a percepção daquilo que a reprodução da imagem ou sua descrição não dão conta de mostrar. Talvez possamos comparar a experiência da visualidade artística de uma exposição à da leitura de um livro. Por mais que nos narrem a história, jamais será o mesmo que a ler. Estar na presença da obra é um acontecimento insubstituível, portanto, intransferível.

Dessa forma, é possível afirmar que olhar para a obra sem a interferência da reprodução técnica nos possibilita ver com e por profundidade: as materialidades, as superfícies, as dimensões, as formas, as estruturas, as cores, as texturas, a ambientação, sentir os aromas, o espaço, os vazios e os cheios, os ruídos e os silêncios elementos não menos importantes para a fruição estética.

De certa forma, ao visitarmos uma Sala ou Museu, já sinalizamos nossa disposição para ver. Tiburi (2004) observa que "só podemos ver quando aprendemos que algo não está à mostra e podemos sabê-lo", por isso, visitar uma exposição pode ser uma experiência além de lúdica e estética, cognitiva, pois, além de deparar-se com a 
arte, que por si só já é um intenso "estranhamento", há também a percepção do modo como artistas e curadores organizam os objetos e sugerem ou provocam "o percurso" do visitante. Visitar uma exposição artística é uma experiência no mínimo inquietante, porque "se as artes nos ensinam a ver - olhar é porque nos possibilitam camuflagens e ocultamentos" (TIBURI, 2004) e o modo como a arte se mostra assume, muitas vezes, também uma função de conduzir o olhar para visualidades desejadas, mas deixando "margens" para o sujeito se mover.

A professora Miriam Celeste Martins (2005, p. 15) destaca "que nem sempre nos damos conta das complexas relações que podem ser estabelecidas entre nossa fruição e a produção artística. Relações que podem ser superficiais na constatação do 'gosto' ou 'não gosto', ou que podem nos levar a um intenso e inquieto trabalho de construção de sentidos". Instigar um olhar apressado e superficial e torná-lo um olhar atento, curioso e "estrangeiro" é um dos desafios da tarefa de mediação em salas e museus.

Se o mediador precisa instigar um olhar "curioso e estrangeiro", como podemos fazê-lo na medida em que o público que frequenta exposições é diversificado e com níveis de conhecimento diferentes? Aqui cabe uma consideração sobre a capacidade do mediador em entender e atender o público e, para isso, sempre que possível, deve-se construir mecanismos de agendamento com informações básicas que possibilitem prever as características e objetivos do grupo visitante para proporcionar um atendimento que corresponda às expectativas, mesmo que isso não garanta o sucesso da tarefa. Para entender um pouco a complexidade da tarefa em torno da "educação do olhar", vale pensar sobre o modo como Tiburi (2004), problematiza o olhar e o ver, que são pressupostos para a apreciação.

A lentidão é do olhar, a rapidez é própria ao ver. O olhar é feito de mediações
próprias à temporalidade. Ele sempre se dá no tempo, mesmo que nos remeta a
um além do tempo. Ver, todavia, não nos dá a medida de nenhuma temporalidade,
tal o modo instantâneo com que o realizamos. Ver não nos faz pensar, ver nos
choca ou nem sequer nos atinge. As mediações do olhar, por sua vez, colocam-no
no registro do corpo: no olhar - ao olhar - vejo algo, mas já vitimado por tudo o
que atrapalha minha atenção retirando-a da espécie sintética do ver e registrando-
a num gesto analítico que me faz passear por entre estilhaços e fragmentos a
compor - em algum momento - um todo. O olhar mostra que não é fácil ver e que
é preciso ver, ainda que pareça impossível, pois no olhar o objeto visto aparece em
seus estilhaços de ser e só com muito custo é que se recupera para ele a síntese
que nos possibilita reconstruir o objeto. É como se depois de ver fosse necessário
olhar, para então, novamente ver. Há, assim, uma dinâmica, um movimento -
podemos dizer - um ritmo em um processo de olhar-ver. Ver e olhar se
complementam, são dois movimentos do mesmo gesto que envolve sensibilidade e
atenção.

Além de proporcionar a fruição, é também tarefa da mediação provocar os sujeitos para olhar/ver/perceber aquilo que está visível e também oculto na obra e que pode ser apreendido na "escavação" para a construção de sentidos. Buscar encontrar as questões em torno das obras, das ideias do artista, das pesquisas por ele desenvolvidas, das perguntas que ele fez e nos faz, é apostar que através do olhar, que busca o ver, algo se descortine. Quando tratamos de apreciação artística e estética, ou seja, a que 
pode acontecer nas Salas e nos Museus, enfatiza-se a dimensão do olhar/ver e, é fundamental que haja uma disposição para ver aquilo que a obra mostra, mas também para transver ${ }^{10}$ aquilo que nós podemos construir ao sentir, pensar e imaginar a partir da obra ou com a obra. Para o artista Iberê Camargo (2008), "A memória é a gaveta dos guardados. Nós somos o que somos, não o que virtualmente seríamos capazes de ser. Minha bagagem são os meus sonhos" (MARTINS, 2005, p. 25). Por isso, é possível afirmar que na presença da obra nosso horizonte se funde com o dela e convocamos nosso repertório para construir significações, pois para Gadamer (Apud PALMER, 1989, p.175) "a arte situa-se. Exige um lugar e cria para si mesma um lugar aberto".

$\mathrm{E}$, nesse sentido, é importante destacar o olhar para além do aspecto físico, mas, principalmente, como uma ação humana subjetiva, psicológica e cultural. Novamente mencionamos as ideias de Tiburi (2004), pois "quando chamo alguém para olhar algo espero dele uma atenção estética, demorada e contemplativa, enquanto ao esperar que alguém veja algo, a expectativa se dirige à visualização, ainda que curiosa, sem que se espere dele o aspecto contemplativo. Ver é reto, olhar é sinuoso. Ver é sintético, olhar é analítico. Ver é imediato, olhar é mediado". Essa predisposição e atenção para olhar/ver são fundamentais para aquilo que entendemos como "leitura de imagem" que, na essência, é o que ocorre a partir da mediação.

Se o olhar é também cultural, podemos ensinar a olhar, na medida em que proporcionamos experiências de visualidades que intencionem a observação, o estranhamento e a conexão com ideias e pensamentos. Aprendemos a olhar em diferentes contextos e nesse sentido a tarefa de mediação cumpre sua função quando desinstala o olhar da ordem do cotidiano e conecta com o campo da arte e da cultura, proporcionando a experiência estética que é transgressora, radical e poética.

Quando observamos o público apreciando uma exposição, percebemos fundamentalmente que seu olhar se inquieta, que se modifica. Esse olhar que busca ver, se aproxima, se afasta, espiona, duvida, suspeita, se deleita. O corpo explicita um estado de perturbação, que, por vezes, suspeita da obra e, por vezes de si. Por instantes, parece que algo fica suspenso e isso é fundamental para acontecer o encontro entre a obra e o sujeito. Um encontro que não será necessariamente cordial, mas será inevitavelmente transformador. Mais uma vez, Tiburi (2004) nos ajuda a compreender o que acontece:

O olhar diz-nos que não temos o objeto e, todavia, nos dispõe no esforço de
reconstituí-lo. O olhar nos faz perder o objeto que visto parecia capturado. Para
que reconstituí-lo? Para realmente capturá-lo. Mas essa captura que se dá no olhar
é dialética: perder e reencontrar são os momentos tensos no jogo da visão. Há,
entretanto, ainda outro motivo para buscar reconstruir o objeto do olhar: para não
perder além do objeto, eu mesmo, que nasço, como sujeito, do objeto que

${ }^{10}$ Transver é um termo usado pelo poeta Manoel de Barros para se referir ao pensamento, imagens e fantasias que construímos a partir da imaginação, do sentimento, das ideias. Ver documentário de João Jardim/Walter Carvalho "Janela da Alma". 
contemplo - construo enquanto contemplo. Olhar é também uma questão de sobrevivência.

A experiência do olhar é algo do qual podemos extrair prazer e autoconhecimento, e com essa afirmação justificamos a tarefa de mediação como mais uma possibilidade de ampliação das nossas experiências de vida. Desse modo, mediadores/educadores assumem a responsabilidade de proporcionar a visualidade para a compreensão crítica da arte e da cultura. Ao ler, geralmente, observamos, analisamos e interpretamos a imagem/obra e, para isso, também convocamos nosso imaginário e nosso repertório, produzimos os significados a partir destas relações. Mas também, devemos pensar que a "obra também nos olha", que ela é pregnante de sentidos. A beleza da tarefa da mediação é que seguidamente percebemos que somos pegos pela obra, que não temos a autonomia que acreditamos possuir em relação a ela. Algumas vezes, inclusive, ela nos arrebata. Para Gadamer (apud PALMER, 1989, p.172), "[...] é a obra de arte que nos coloca uma questão, a questão que provocou o seu ser. A experiência de uma obra de arte é englobante e surge na unidade e continuidade do nosso próprio autoconhecimento".

Perceber a obra requer exercício de olhar/ver, vivência de apreciação e o cultivo de um olhar sensível e pensante. Ver exige profundidade para perceber as articulações compositivas e perceber que "a arte não é sem tempo nem sem lugar" (GADAMER apud PALMER, 1989, p. 175). Olhar o objeto e perceber suas relações com o sistema simbólico que the dá significado e observar que o significado é trazido para a linguagem criando sentidos de acordo com o contexto de informações do leitor: capacidade de inferências, articulação de informações e relacionamento de ideias e valores. Para Hernández (2000, p. 114), as imagens, assim como a arte, estão sujeitas "a uma atribuição de significados pois não só expressa o que o artista tem em sua 'mente' no momento em que está realizando a obra, mas inclui a interpretação do espectador, que também contribui para dar sentido a experiência estética".

Neste mundo, mediado por imagens, investir na educação do olhar é um dos desafios dos formadores e educadores. Além dos espaços formais de aprendizagem, as salas e museus cumprem uma tarefa importantíssima ao proporcionarem ambientes diversificados de apreciação e aprendizagem, pois ali está obra e objeto à espera do olhar pensante. Nem museus, nem salas se justificam sem o público. Assim como, para Gadamer (apud PALMER, p. 175), "as obras não pertencem aos museus, onde são reunidas num lugar não localizado", pois elas foram criadas por alguém, num tempo/espaço que necessita ser trazido para a compreensão. Reside aí o desafio de justificar a presença do mediador: estar entre obra e público na justa medida que a tarefa permite. 


\section{Considerações finais}

Ao desenvolver a tarefa de mediação no contexto da pesquisa aqui relatada, nos indagamos sobre o que acontece com o estudante a partir da vivência com a obra em uma sala de exposição. Temos observado que a atividade de mediação, em que se estabelece um percurso de visualização mediada por questões, ideias, provocações visuais e atividades plásticas desperta no estudante uma fala expressiva na qual manifesta sua compreensão, suas visões sobre arte, sobre o cotidiano e sobre si mesmo. Essas manifestações são entendidas por nós como aprendizagens, conhecimentos sobre arte, cultura visual e sobre a dimensão sensível do sujeito que está diante da obra, convocando seus repertórios para interagir, contextualizar, interpretar e produzir sentido.

Sendo assim, consideramos que as salas de exposições e museus possibilitam a ampliação dessa experiência, pois nelas se mostram os objetos, ali estão às obras e os objetos da cultura. Frequentar exposições deve fazer parte da constituição educativa artística e cultural dos estudantes e dos professores, enfim, da formação intelectual do sujeito.

Apreciar obras de arte não deveriam ser experiências para alguns privilegiados que podem gozar de passeios e/ou viagens com suas famílias, ou para uma classe social que frequenta escolas privadas, e que, por isso, geralmente possuem mais condições de passeios artístico/culturais, mas sim, uma experiência estética e educativa que constitui o sujeito como ser de cultura, como parte da sua formação humana. No Brasil isso ainda é visto como luxo, desfrute ou "coisa de rico". Falta-nos ampliar essa questão também em nível de educação superior e inserir isso como elemento de formação dos futuros professores, pois a grande maioria dos estudantes universitários não frequenta museus e nem salas de exposições. Se tomarmos como referência a Sala de Exposição Java Bonamigo, podemos afirmar, inclusive, que a maioria dos professores universitários não foi em suas exposições, desconhecem sua proposta e não articulam suas mostras/acervo com as áreas de conhecimento do ensino superior.

É indiscutível que o professor necessita de uma bagagem cultural para conseguir estabelecer relações entre a especificidade de sua área de conhecimento com o conhecimento geral, com as razões humanas para a criação do conhecimento. No entanto, a arte parece ser um luxo ou um "aspecto exótico" da vida em sociedade, e não uma linguagem que evidencia diferentes formas de manifestar a condição humana.

Temos percebido que os estudantes e/ou futuros professores que frequentam a sala de exposição, com o auxílio de um mediador, logo percebem a riqueza de possibilidades que ali se apresentam. Lembramos de uma vivência de mediação com uma turma de estudantes do ensino superior do Curso de Pedagogia, em que ficou evidente a carência de compreensão da arte, das materialidades, das ideias, do próprio 
entendimento de exposição. Ao serem instigadas a olhar com atenção e disposição para ver, relacionando as obras com o espaço, com o cotidiano e a cultura, foram percebendo nuances que lhes desvelaram "mundos". Quantas coisas passaram a fazer sentido, quantas formas conseguiram perceber, quantas ideias ocorreram e como se sentiram "capazes de falar" sobre o que viam e sentiam, pois, num primeiro momento, era visível o estranhamento, e o que mais expressavam era que "não entendiam nada daquilo", que nunca haviam apreciado uma exposição de arte contemporânea.

Sendo assim, entendemos a tarefa de mediação como um esforço hermenêutico dos sujeitos na relação entre a obra e o contexto da significação. Mediação é a situação criada para querer "entender" a obra. É proposição articulada a algum tema, fato ou ideia. É ação intersubjetiva diante de um problema que nos propomos a debater e também a compreender. Dessa forma, podemos dizer que a mediação gera cumplicidade, pois ela é um acontecimento que necessita de envolvimento, se faz no processo, na própria experiência com o objeto. Ela necessita de trabalho coletivo, de problematização e construção de alternativas e respostas (mesmo que provisórias) no e do coletivo. Intersubjetividade que não preconiza o "controle do olhar" mas, potencializá-lo, alargálo, é "ver-junto" para que as singularidades se enriqueçam.

\section{Referências}

BARBOSA, A. M. As mutações do conceito e da prática. In: BARBOSA, A. M. (org.). Inquietações e mudanças no ensino da arte. São Paulo: Cortez, 2002. p. 13-25.

AMARAL, L. (orgs.). Interterritorialidade: mídias, contexto e educação. São Paulo: Senac, 2008.

COELHO, T. Dicionário crítico de política cultural. 1999.

COUTINHO, R. G. (orgs.). Arte/educação como mediação cultural e social. São Paulo: Ed. UNESP, 2009.

HERNÁNDEZ, F. Catadores da cultura visual: proposta para uma nova narrativa educacional. Porto Alegre: Mediação, 2009.

LISBOA, A. Construção de uma metodologia para mediação: uma experiência no Instituto de Arte Contemporânea da UFPE. In: MEDEIROS, M. B. (org.). Arte em pesquisa: especificidades. Brasília: ANPAP, 2004. v. 2.

MARTINS, M. C. Conceitos e terminologia - aquecendo uma transforma-ação: atitudes e valores no ensino de arte. In: BARBOSA, A. M. (org.). Inquietações e mudanças no ensino da arte. 2. ed. São Paulo: Cortez, 2003. p. 49-60.

Curadoria educativa: uma pesquisa com educadores. In: MARTINS, A. F.; COSTA, L. E.; MONTEIRO, R. H. (orgs.). Cultura visual e desafios da pesquisa em artes. Goiana: ANPAP, 2005. 
Mediação: provocações estéticas. Universidade Estadual Paulista. Instituto de Artes. Pós-Graduação. São Paulo, v. 1, n. 1, out. 2005.

PALMER, Richard E. Hermenêutica. Lisboa: Edições 70, 1989.

TIBURI, M. Aprender a pensar é descobrir o olhar. Artigo originalmente publicado pelo Jornal do Margs, edição 103, set./out. 2004. 